\title{
Barium Sulfate Aspiration mimicking Tracheo-esophageal Fistula in a 82 years Aged Man
}

\author{
PULAK KUMAR JANA, ${ }^{1}$ TAPAN DAS BAIRAGYA, ${ }^{2}$ IRA DAS, ${ }^{3}$ SURAJIT CHATTERJEE ${ }^{4}$
}

A 82 year aged male non-diabetic, non-hypertensive suffering from fever, skin rash diagnosed clinically as chicken-pox was admitted with complain of decreased appetite, sudden onset of breathlessness and cough after taking food and drink. There was one episode of generalised convulsion.

Investigation shows WBC 7740/ cmm, N 76\%, L 18\%, M4\%, $\mathrm{E} 2 \%$, Kidney, liver and thyroid functions were normal. Sputum shows significant growth of E. Coli and Klebsiella . Chest XRay was normal. USG abdomen showed prostatomegally, HIV $1 \& 2$ were non reactive. Barium swallow showed no flow of barium in mid and lower oesophagus and passage of barium into tracheo-bronchial tree suggestive of tracheo-oesophageal fistula (Fig. 1). Upper GI endoscopy was done twice and no abnormality was detected. CT and MRI Brain showed normal reports. Serology for Dengue IgM, IgG - non reactive, IgM

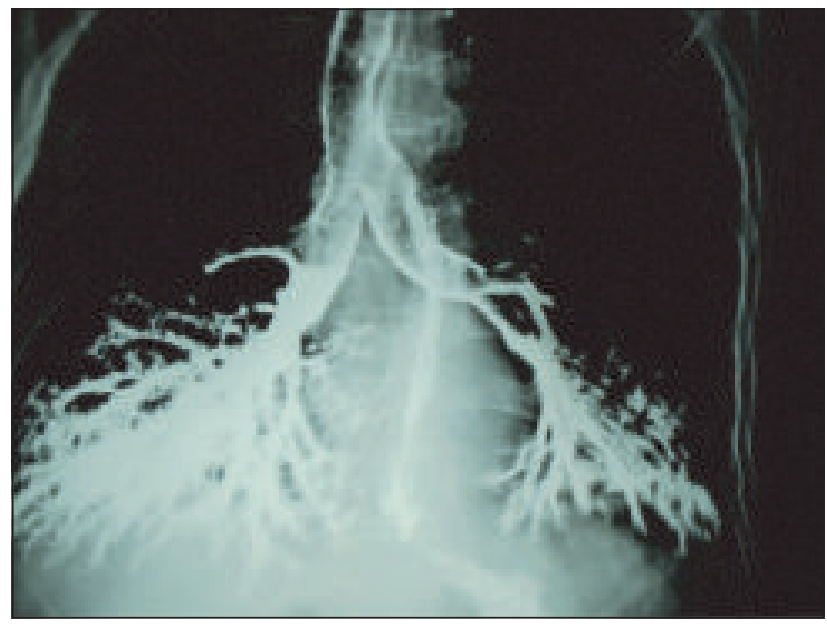

Fig -1. Barium in tracheo- bronchial tree, mimicking bronchography.

1. Associate Professor, Department of Chest Medicine, Institute of Post Graduate Medical Education \& Research, Kolkata, 244 A.J .C. Bose Road, Kolkata -700020, West Bengal, India

2. Assistant Professor, Dept. of Chest Medicine, North Bengal Medical College. Darjeeling, West Bengal

3. Medical Officer, Department of Paediatric Medicine, Medical College, Kolkata

4. Assistant Professor, Department of Chest Medicine, Institute of Post Graduate Medical Education \& Research, Kolkata, 244 A .J .C. Bose Road, Kolkata -700020, West Bengal, India,

Correspondence: Dr Pulak Kumar Jana, Deeshari Comfort, Flat -1/1A, 732 Sreenagar West, Kolkata-700094, Near Mangalik Bhavan, New Garia Housing Coperative, West Bengal , India, Emaildoctorjana_23@yahoo.com
Japanese Encephalitis - non reactive. CSF - normal including ADA 0.5/1 and oligoclonal band was negative. CT scan Thorax (Fig.2) which was done after 3 weeks showed contrast bronchogram with consolidation both lower lobes, middle lobe right side, lingular segment left side and reduction of density of barium in axial scanogram (Fig.3). EMG neck showed active

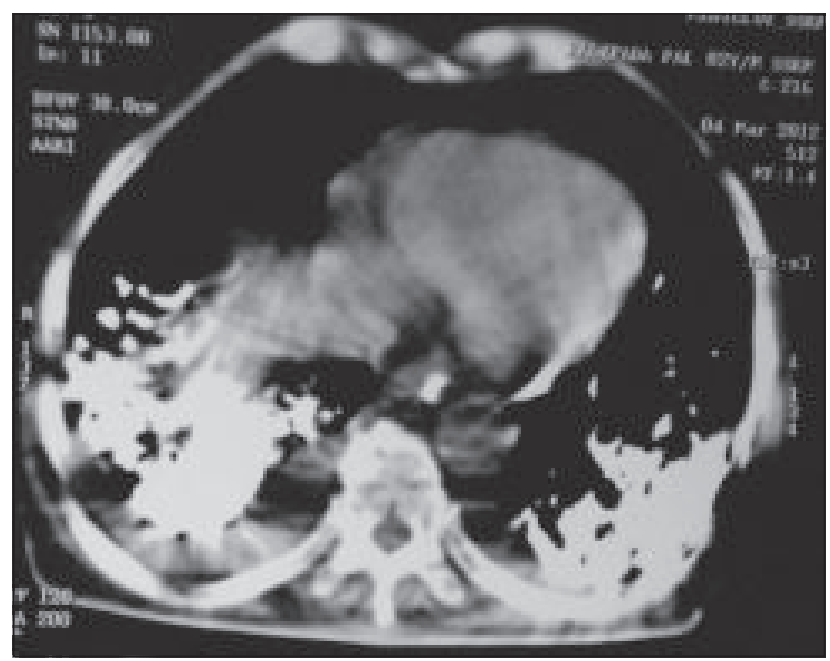

Fig-2. CT scan showed contrast bronchogram with consolidation both lower lobes, middle lobe right, minimal pleural effusion in right side.

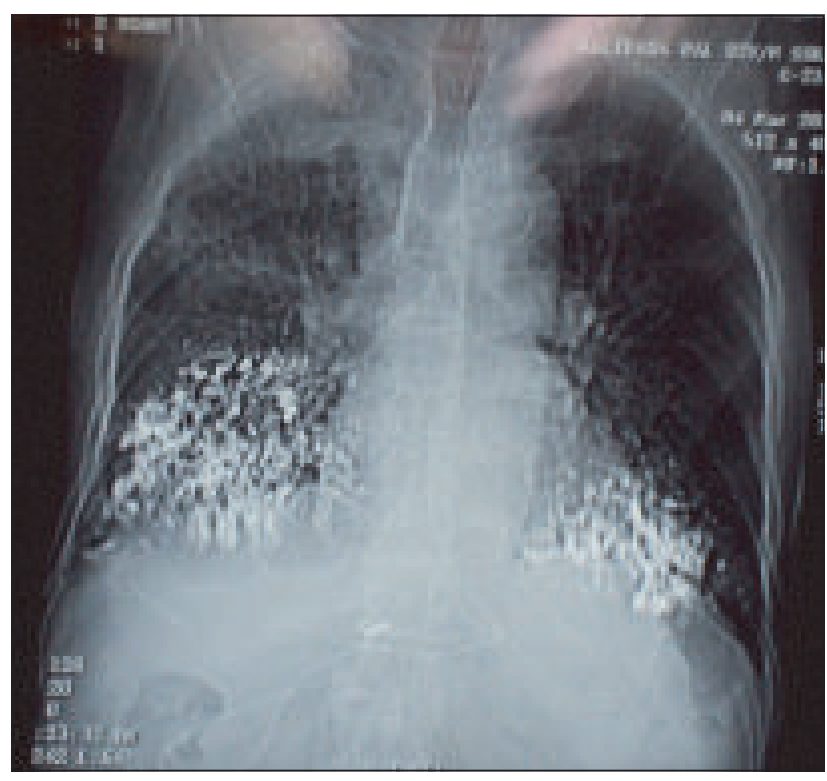

Fig-3. Axial scanogram showing intra alveolar barium sulphate, especially in both lower lobes. 
denervation of all the muscles of neck suggestive of anterior horn cell disease. In our case the aged man have developed bulbar palsy after chicken pox for which aspiration of barium was occurred during barium examination. He was well and discharged after 6 weeks hospital stay.

It is rare that during upper gastrointestinal radiographic contrast procedure large amounts of barium sulphate are accidentally aspirated into the lung. ${ }^{1}$ Duo to inert character of barium sulphate no lung injury usually occur but acute inflammation of the bronchial wall can occur due to high density preparations $(250 \% \mathrm{w} / \mathrm{v})$. Generally no late toxicities (e.g. lung fibrosis) have been identified. If acute hypoxemia develops bronchoscopy recommended to extract barium sulphate from tracheo bronchial tree. ${ }^{2}$

\section{Conflict of Interest: none}

\section{References:}

1. Lareau DG, Berta JW. Fatal aspiration of thick barium. Radiology 1976; 120:317.

2. Ingo Tamm, Cornelius Kortsik. Severe Barium Sulfate Aspiration into the Lung: Clinical Presentation, Prognosis and Therapy. Respiration 1999;68:81-84. 